\title{
As Grandes Cidades e Suas Contradições Internas: A Sociologia Urbana de Friedrich Engels
}

The Great Cities and Their Internal Contradictions: The Urban Sociology of Friedrich Engels

\author{
Wallace Cabral Ribeiro ${ }^{1}$
}

\section{RESUMO}

Friedrich Engels, em sua obra A Situação da Classe Trabalhadora na Inglaterra (1844/45), verificou uma série de mazelas que constituem a vida das grandes cidades, como o adensamento populacional, desigualdades sociais, segregação espacial, déficit habitacional, miséria, violência, individualismo, epidemias, poluição, desemprego etc. Ao analisar todos esses fenômenos, sua obra se orientou por múltiplos campos de conhecimento, como história, antropologia, ecologia, política, economia, epidemiologia, entre outras. Este artigo tem como objetivo identificar e analisar as contribuições de Engels para o campo da sociologia urbana, na clássica obra acima mencionado.

PALAVRAS-CHAVE: Sociologia Urbana; as grandes cidades; contradições sociais; urbanização; industrialização.

\begin{abstract}
Friedrich Engels, in his work The Situation of the Working Class in England (1844/45), verified a series of problems that constitute the life of big cities, such as population density, social inequalities, spatial segregation, housing deficit, poverty, violence, individualism, epidemics, pollution, unemployment, etc. In analyzing all these phenomena, his work was guided by multiple fields of knowledge, such as history, anthropology, ecology, politics, economics, epidemiology and others. This article aims to identify and analyze Engels' contributions to the field of urban sociology in the classic work above mentioned.
\end{abstract}

KEYWORDS: Urban Sociology; the big cities; social contradictions; urbanization; industrialization.

1 Mestre em sociologia pela Universidade Federal Fluminense (PPGS - UFF), bacharel em Sociologia pela mesma instituição, consultor da Revista Ensaios, membro do Núcleo de Estudos Friedrich Engels (NEFE), do Laboratório de Estudos Socioantropológicos em Política Arte e Religião (LePar) e do Núcleo de Estudos Cidadania, Trabalho e Arte (Nectar - UFF). Email: cabralwallaceribeiro@yahoo.com.br 
Cadernos de Estudos Sociais e Políticos, Rio de Janeiro, vol. 6, 2018.

\section{INTRODUÇÃO}

Ao longo de toda sua vida, Friedrich Engels dedicou-se à luta política em favor da classe operária. Em sua trajetória político-intelectual, estudou os diversos processos interligados à formação histórica do capitalismo. Ao debruçar-se sobre esta tarefa, se dedicou aos mais variados temas. Em sua vasta obra, é possível encontrar conhecimentos relacionados às áreas de sociologia da religião, história, antropologia, ciência política, economia, ciências naturais, biologia evolutiva, física, química, educação, relações de gênero, ciências jurídicas, epidemiologia, filosofia, astronomia, ciências militares, entre outros campos do saber. A algumas dessas áreas, às quais Engels se dedicou com mais afinco, e, por isso, contribuiu mais significativamente, desenvolveu ideias originais e iconoclastas: este é o caso da sociologia urbana.

No final da década de 1830, Engels teve uma rica experiência quando investigou e analisou as condições de vida dos operários na cidade de Wuppertal, na Alemanha. Em 1839, com apenas 18 anos, publicou no periódico Telagraph für Deutschland, as Cartas de Wuppertal, assinando-as com o pseudônimo de Friedrich Oswald. Segundo Hunt, esses textos "eram de uma autenticidade ímpar, uma experiência de testemunha ocular naquela região deprimida, embriagada e desmoralizada" (2010, p. 49), "as 'Letters' são uma crítica magnífica e brutal dos custos humanos do capitalismo" (Op. cit., p. 50).

Nesses textos, Engels já relatava com vivacidade as circunstâncias em que se encontravam os trabalhadores de Wuppertal, apontando para as péssimas condições de trabalho, alcoolismo, degradação moral, precariedade da educação, contraste entre miséria e opulência, doenças e também uma densa crítica à religião, como pode ser verificado nesta passagem:

\footnotetext{
Entre as classes inferiores prevalece uma miséria terrível, particularmente entre os trabalhadores das fábricas de Wuppertal; a sífilis e as doenças pulmonares são tão generalizadas que é difícil de acreditar; somente em Elberfeld, das 2.500 crianças em idade escolar, 1.200 são privadas da educação e crescem nas fábricas, apenas para que o fabricante não precise pagar a um adulto, que custa, o dobro do salário que ele paga a uma criança. (Engels, 1975, p. 10, tradução livre).
}

Nesse momento, Engels ainda não era comunista nem materialista, mas já demonstrava uma forte inclinação aos problemas sociais existentes na sociedade. "O mais importante nas Cartas de Wuppertal é a crítica das relações sociais" (Instituto de Marxismo-Leninismo CC-PCUS, 1986, p. 22). 
Cadernos de Estudos Sociais e Políticos, Rio de Janeiro, vol. 6, 2018.

Outra experiência importante para a sociologia urbana é de um Engels amadurecido, comunista e materialista, em seu texto Contribuição ao Problema da Habitação, de 1872/73. Nesse texto, Engels discute a crise da habitação como um problema crônico do capitalismo:

\begin{abstract}
O que hoje se entende por escassez de habitação é o particular agravamento das más condições de moradia dos operários em consequência da afluência repentina de população para as grandes cidades; é um formidável aumento dos aluguéis, uma maior aglomeração de inquilinos em cada casa e, para alguns, a impossibilidade total de encontrar abrigo. (ENGELS, 1976, p. 50)
\end{abstract}

Apesar de o autor ter contribuído enormemente para este segmento da sociologia, do ponto de vista qualitativo e quantitativo, este trabalho se limitará a abordar a sociologia urbana em sua obra A Situação da Classe Trabalhadora na Inglaterra, de 1844/45.

Uma das características de fundamental importância nessa obra é a variabilidade das fontes de informação, que vão desde relatórios de inspetores fabris até a imprensa socialista, como o periódico Northen Star. Além disso, "Engels fez uso de depoimentos orais e da observação direta das condições de vida e de trabalho dos trabalhadores, obtendo, com tais procedimentos, um conhecimento mais profundo e minucioso da condição operária” (Castellucci, 2007, p. 22).

Ao desembarcar na Inglaterra, Engels rapidamente desenvolveu uma militância junto aos movimentos operários, o que lhe permitiu conhecer a realidade dos trabalhadores. Outro fator de suma importância para que Engels conhecesse de uma forma mais intensa a realidade dos proletários foi seu relacionamento com Mary Burns, que lhe proporcionou conhecer pessoalmente os bairros operários e verificar, na observação direta, as reais condições de vida do operariado inglês. Segundo Hunt, "Mary Burns representou para ele o papel de Perséfone, enriquecendo profundamente a visão de Engels sobre a sociedade capitalista” (2010, p. 115). De acordo com José Paulo Netto, a inserção de Engels nos meios proletários se deu por conta de "sua relação com Mary Burns, emigrante irlandesa e operária. Aquela que seria sua primeira mulher abre-lhe as portas do meio proletário e os seus contatos se multiplicam" (2004, p. 36).

Metodologicamente, Engels adota uma abordagem dialética sobre uma série de expressividades das grandes cidades industriais, na qual procura destrinchar analiticamente cada uma delas no sentido de tentar elucidar suas dinâmicas internas, interconectado-as organicamente. Existe, em A Situação (2010), uma combinação, um entrelaçamento entre diversas técnicas de investigação, a destacar: a bibliográfica, via livros e artigos; a documental, consultando relatórios parlamentares, relatórios médicos, inquéritos policias, a grande imprensa, periódicos socialistas; e a etnográfica, com visitações a bairros operários, e observações diretas da dinâmica das cidades, do 
Cadernos de Estudos Sociais e Políticos, Rio de Janeiro, vol. 6, 2018.

comportamento coletivo e das mazelas sociais. A combinação entre essas técnicas de investigação fez d'A Situação uma obra original, única e destacada, que favoreceu um rápido amadurecimento ao jovem Engels, tanto do ponto de vista intelectual quanto do político/militante. Lênin, em um escrito de 1913, em que comenta sobre a publicação das correspondências entre Marx e Engels, afirma que $A$ Situação "é uma das melhores obras na literatura socialista mundial” (2016, s.p.).

N'A Situação, é apontada a base social para o avanço da urbanização em diversas cidades, compreendendo o fenômeno urbano não como algo natural que possui uma essência em si, mas uma construção artificial humana. Robert Ezra Park (1967), um dos maiores expoentes da sociologia urbana e pertencente à escola de Chicago, muitas décadas depois, concebeu em seu sistema de pensamento ideias similares às do jovem Engels. Isso pode ser verificado nas seguintes passagens de seu clássico texto $A$ Cidade: "a cidade não é meramente um mecanismo físico é uma construção artificial. Está envolvida nos processos vitais das pessoas que a compõem; é um produto da natureza, e particularmente da natureza humana" (PARK, 1967, p. 25). Neste outro trecho, a semelhança de ideias é ainda maior:

\footnotetext{
A cidade, e especialmente a grande cidade, onde mais do que em qualquer outro lugar as relações humanas tendem a ser impessoais e racionais, definidas em termos de interesse e em termos de dinheiro, é num sentido bem real um laboratório para a investigação do comportamento coletivo. As greves e movimentos revolucionários menores são endêmicos no meio urbano. As cidades, e especialmente as cidades grandes, estão em equilíbrio instável. O resultado é que os enormes agregados casuais e móveis, que constituem nossas populações urbanas, estão em estado de perpétua agitação, varridos por todo novo vento de doutrina, sujeitos a alarmas constantes e, em consequência, a comunidade está numa condição de crise crônica (Park, 1967, p. 44).
}

Existem outros aspectos que aproximam Engels e Park, como por exemplo, a investigação sobre a constituição física da cidade, os hábitos e os costumes dos trabalhadores, a contradição entre bairros opulentos e miseráveis, a cidade como uma unidade econômica. Mas cada autor com suas particularidades. Em relação ao último aspecto mencionado, Park compreende que "a cidade não é apenas uma unidade geográfica e ecológica; ao mesmo tempo, é uma unidade econômica. A organização econômica da cidade baseia-se na divisão do Trabalho” (Op.cit., p. 26). Engels também entende que existe uma organização interna da cidade através da divisão do trabalho, tanto no que diz respeito ao fracionamento da produção, quanto em categorias profissionais. Porém, esse autor chega à conclusão que o próprio surgimento dos grandes centros urbanos está intimamente relacionado à divisão do trabalho estabelecida pela revolução industrial que aguçou as diferenças entre o campo e a cidade. 
Cadernos de Estudos Sociais e Políticos, Rio de Janeiro, vol. 6, 2018.

É importante ressaltar que, apesar de A Situação ser uma obra de grande valor científico, Engels a desenvolve em um contexto de militância política; ou seja, a dimensão científica da obra está submetida à dimensão política, já que o que mais interessa ao "General", não é compreender a sociedade por si só, mas compreendê-la para apontar saídas revolucionárias das formas de organização societária.

Para Hobsbawm, A Situação é uma obra que, pela primeira vez, trata "da classe operária como um todo e não somente de determinados segmentos e setores industriais” (2011, p. 52) e "não se tratava de um mero levantamento das condições da classe operária, mas de uma análise geral da evolução do capitalismo industrial, do impacto social da industrialização e de suas consequências políticas e sociais - inclusive do crescimento do movimento operário" (Ibidem). As ideias embrionárias contidas nessa obra foram fundamentais para formulações de concepções políticas, filosóficas, científicas, econômicas e metodológicas que serviram de base para o desenvolvimento do materialismo histórico. É “a primeira tentativa em grande escala de aplicar o método marxista ao estudo concreto da sociedade e, provavelmente, a primeira obra de Marx ou Engels que os fundadores do marxismo julgavam ter valor suficiente para merecer preservação permanente" (Ibidem).

Um conjunto de concepções encontradas em A Situação já se encontrava no Esboço de uma crítica da economia política, publicado nos Anais Franco Alemães em 1844. Esse texto foi fundamental para a criação da parceria Marx/Engels. Wanderson Fabio de Melo observa que nesse artigo

\footnotetext{
o jovem autor evidenciou a diferenciação crescente das classes sociais, as crises cada vez mais graves e a vinculação de todas as contradições econômicas à propriedade privada. Sendo assim, após realizar a crítica das categorias econômicas da economia política, Engels, por meio d'A situação da classe trabalhadora na Inglaterra, revelou as contradições e antagonismos da sociedade burguesa. (Melo, 2015, p. 140)
}

\section{AS GRANDES CIDADES E SUAS CONTRADIÇÕES INTERNAS}

$\mathrm{Na}$ introdução de $A$ Situação, Engels esboça brevemente como eram as condições de vida dos trabalhadores antes de sua proletarização com a Revolução Industrial. De acordo com o fundador da "filosofia da práxis",

1 Apelido dado a Engels devido aos seus inúmeros textos militares, ao fato de ter sido militar voluntariamente quando jovem, por ser organizado, disciplinado e de porte físico militar. 
Cadernos de Estudos Sociais e Políticos, Rio de Janeiro, vol. 6, 2018.

\begin{abstract}
os trabalhadores sobreviviam suportavelmente e levavam uma vida honesta e tranquila, piedosa e honrada; sua situação material era bem superior à de seus sucessores: não precisavam matar-se de trabalhar, não faziam mais do que desejavam e, no entanto, ganhavam para cobrir suas necessidades e dispunham de tempo para um trabalho sadio em seu jardim ou em seu campo, trabalho que para eles era uma forma de descanso; e podiam, ainda, participar com seus vizinhos de passatempos e distrações - jogos que contribuíam para a manutenção de sua saúde e para o revigoramento de seu corpo. (Engels, 2010, p. 46)
\end{abstract}

Apesar desses trabalhadores (tecelões camponeses) serem pobres, suas condições de vida eram mais saudáveis do que as do "moderno operário", pois tinham um pouco mais de autonomia sobre sua produção, "seus filhos cresciam respirando o ar puro do campo e, se tinham de ajudar os pais, faziam-no ocasionalmente, jamais numa jornada de trabalho de oito ou doze horas" (Ibidem). A grande diferença assinalada entre o proletariado e o camponês não é a pobreza em si, pois ambos eram pobres, mas a classe trabalhadora, por conta da concorrência capitalista desenfreada, possui "uma vida de profunda insegurança, na qual o futuro é absolutamente desconhecido e incerto" (Hobsbawm, 2011, p. 75-6), enquanto que o camponês gozava de uma relativa "segurança" em relação a sua existência material.

Esses pobres camponeses, "sentiam-se à vontade em sua quieta existência vegetativa e, sem a revolução industrial, jamais teriam abandonado essa existência, decerto cômoda e romântica, mas indigna de um ser humano” (Engels, 2010, p. 47). A Revolução Industrial ${ }^{2}$ arrancou das mãos dos camponeses seus "últimos restos de atividade autônoma" e, precisamente por isso, na posição de proletários, se viram obrigados "a pensar e a exigir uma condição humana" (Ibidem).

Para o socialista alemão, "a revolução industrial teve para a Inglaterra a mesma importância que a revolução política teve para a França e a filosofia para a Alemanha” (Op. cit., p. 58-9). Afirma veementemente que "o fruto mais importante dessa revolução industrial, porém, é o proletariado inglês" (Op. cit., p. 59) Aqui, Engels já enxerga o proletário como um agente transformador. A "existência vegetativa" é substituída por uma existência pensante e atuante sobre a realidade, que "deverá explodir numa revolução diante da qual a primeira Revolução Francesa e $1794^{3}$ serão uma brincadeira de crianças" (Op. cit:: 62).

Essa concepção reaparecerá no texto Princípios Básicos do Comunismo (1847), nessa obra Engels afirma que a revolução industrial fez da cidade um espaço de concentração de um grande contingente populacional em que o capital exerce uma exploração mais abrangente e eficiente, mas

2 Revolução industrial - "esta expressão, que será amplamente utilizada muito mais tarde, aparece então, pela primeira vez, sob a pena de Engels" (Lefebvre, 2001, p. 10).

3 "Engels se refere à ditadura jacobina" (nota dos editores). 
Cadernos de Estudos Sociais e Políticos, Rio de Janeiro, vol. 6, 2018.

"esta concentração de grandes massas num mesmo lugar [que] dá ao proletariado a consciência da sua força" (Engels, 1982, p. 22). Ideias similares também aparecem em A Ideologia Alemã (1846) e também no Manifesto do Partido Comunista (1848), demonstrando que a estadia de Engels na Inglaterra foi determinante para suas posições políticas, pois foi lá "que o jovem Engels tornou-se comunista” (Lênin, s.d. apud Netto, 2004, p. 32).

Em uma interessante reflexão sobre o jovem Engels na Inglaterra, José Paulo Netto afirma que este toma a "urbanização moderna como variável da industrialização capitalista e, sobretudo, a cidade como topus do capitalismo constituído" (2004, p. 40). Engels identifica um processo de "urbanização acelerado":

o crescimento demográfico e a urbanização conectam-se diretamente à industrialização - evidencia-o a hipertrofia das cidades industriais que, em apenas quarenta anos (18011841), sofrem o seguinte acréscimo no seu número de habitantes: Manchester - 35 mil/353 mil; Leeds - 53 mil/152 mil; Birmingham - 23 mil/181 mil; Sheffield - 46 mil/111 mil" (Netto, 2004, p. 34)4.

Essas variações populacionais são provocadas diretamente pela dinamicidade industrial. De acordo com Raquel Rolnik, as cidades são como imãs, “um campo magnético, que atrai, reúne e concentra os homens” (1995, p. 12). Para Engels, a atividade industrial é o núcleo de atração das grandes cidades inglesas, pois "onde surge uma fábrica de médio porte, logo se ergue uma vila" (Engels, 2010, p. 64). A indústria possui tal importância na vida da cidade que Engels afirma que "toda fábrica nova construída no campo traz em si o embrião de uma cidade industrial" (Op. cit: 65). De acordo com Henri Lefebvre, Engels atribui o nascimento das grandes cidades industriais e comerciais do império britânico a causas tecnológicas (2001, p. 11). Acompanhando esse raciocínio Eric Hobsbawm, afirma que:

A indústria mecanizada em larga escala exige investimentos de capitais cada vez mais consideráveis, e a divisão do trabalho pressupõe a concentração de um grande numero de proletários. Centros de produção com, tal amplitude, mesmo situados no campo, levam a formação de importantes comunidades; Daí um excedente de mão-de-obra: os salários baixam, o que atrai outros industriais para a região. Por isso, as aldeias transformam-se em cidades que, por sua vez, se desenvolvem em virtude das vantagens econômicas que apresentam aos olhos dos industriais (...). Como a indústria tende a deslocar-se dos centros urbanos para as regiões rurais, onde os salários são mais baixos, este deslocamento e a própria causa da transformação dos campos. (1975, p. 10)

$4 \mathrm{Em}$ A Situação da Classe Trabalbadora na Inglaterra, Engels apresenta uma tabela com variações na densidade demográficas em algumas cidades inglesas, ver 2010, pág. 53. 
Cadernos de Estudos Sociais e Políticos, Rio de Janeiro, vol. 6, 2018.

$\mathrm{Na}$ sua obra a Era do Capital, Hobsbawm afirma que "a cidade era, sem dúvida, o mais impressionante símbolo exterior do mundo industrial, exceção feita à estrada de ferro" (1977, p. 222).

No capítulo “As Grandes Cidades”, Engels percebe uma incoerência, uma singularidade na vida citadina de Londres. Temos uma "aglomeração de 2,5 milhões de seres humanos num só local” (2010, p. 67, grifos são do autor), mas, apesar dessa concentração, existe uma total indiferença entre os indivíduos que se cruzam diariamente: "essa indiferença brutal, esse insensível isolamento de cada um no terreno de seu interesse pessoal é tanto mais repugnante e chocante quanto maior é o número desses indivíduos confinados nesse espaço limitado” (Op. cit., p. 68). Para Lefebvre, Engels logo introduz “o tema da 'multidão solitária' e o da atomização, a problemática da rua" (2001, p. 15). Nas grandes cidades, temos a formação de uma cultura citadina, "a guerra de todos contra todos" (Ibidem). Indiferença, individualismo, falta de empatia são elementos constitutivos das grandes cidades. Outro aspecto salientado por Engels é a miséria dos trabalhadores. Segundo Lefebvre, Engels aponta em sua obra uma miséria indescritível, que se encontra em todas as partes, e é "ao mesmo tempo ocasional (para os indivíduos) e perpétua (para a classe)" (Op. cit., p. 23).

A “indiferença bárbara" e a miséria dos trabalhadores deixam o autor perplexo, a ponto de afirmar que "ficamos assombrados diante das consequências das nossas condições sociais, aqui apresentadas sem véus, e permanecemos espantados com o fato de este mundo enlouquecido continuar funcionando" (Engels, 2010, p. 69). Para Lefebvre, nesse capítulo, "Engels põe a nu todo o horror da realidade urbana" (2001, p. 14).

De acordo com Edmund Wilson (1986), Engels, nutrindo o forte desejo de compreender melhor a dinâmica espacial da cidade de Manchester, resolveu examinar

\footnotetext{
o mapa da cidade e viu que o centro comercial era cercado por um cinturão de bairros operários; depois vinham as belas casas e jardins dos proprietários, que se fundiam gradualmente com o campo; viu também de que modo os proprietários podiam ir de suas casas até a Bolsa sem jamais ter que observar as condições de vida dos operários, porque as ruas pelas quais atravessavam os bairros pobres estavam cheias de lojas que escondiam a miséria e a sujeira que havia por trás delas. (Wilson, 1986, p. 131)
}

Para o fundador do materialismo histórico, a cidade de Manchester foi "construída de um modo tão peculiar que podemos residir nela durante anos, ou entrar e sair diariamente dela, sem jamais ver um bairro operário ou até mesmo encontrar um operário - isso se nos limitarmos a cuidar de nossos negócios ou a passear” (Engels, 2010, p. 88). Os “aristocratas do dinheiro" sempre 
Cadernos de Estudos Sociais e Políticos, Rio de Janeiro, vol. 6, 2018.

apresentam formas de ocultar aos seus olhos a pobreza extrema dos trabalhadores, pois a miséria e a sujeira "são o complemento de seu luxo e de sua riqueza" (Engels, 2010, p. 89). As condições de habitação da burguesia encontram-se numa dimensão diametralmente oposta às condições de habitação dos operários. Engels observa que a alta burguesia "habita vivendas de luxo, ajardinadas (...) por onde corre o sadio ar puro do campo, em grandes confortáveis casas, servidas, a cada quinze ou trinta minutos, por ônibus que se dirigem ao centro da cidade” (Ibidem).

Segundo o "General", em "todas as grandes cidades têm um ou vários "bairros de má fama’ onde se concentra a classe operária” (Op. cit., p. 70). O autor faz uma descrição geral de como são esses bairros:

As piores casas na parte mais feia da cidade; quase sempre, uma longa fila de construções de tijolos, de um ou dois andares, eventualmente com porões habitados e em geral dispostas de maneira irregular (...). Habitualmente, as ruas não são planas nem calçadas, são sujas, tomadas por detritos vegetais e animais, sem esgotos ou canais de escoamento, cheias de charcos estagnados e fétidos. A ventilação na área é precária, dada a estrutura irregular do bairro (...) quando faz bom tempo, as ruas servem aos varais que, estendidos de uma casa a outra, são usados para secar roupa. (Engels, 2010, p. 70)

Enfatizando as contradições entre escassez e abundância, Engels constata que "muitas vezes esses miseráveis refúgios do pior pauperismo se encontram próximos dos suntuosos palácios dos ricos” (2010, p. 71). "Em sua narrativa viva e cheia de cores, Engels entra em mais detalhes, mostrando como na maior parte dos casebres, pertencentes aos operários mais mal-pagos, faltam, também, móveis, camas, lençóis e instalações sanitárias” (Castellucci, 2007, p. 25).

Um grave problema social abordado por Engels é o déficit de habitação: “os que dispõem de todo modo de um teto são mais felizes que aquele que não o tem: todas as manhãs, em Londres, 50 mil pessoas acordam sem a menor ideia de onde repousarão a cabeça na noite seguinte” (Engels, 2010, p. 75). Uma parte dos trabalhadores, que, por sorte, consegue um pouco de dinheiro para custear uma estadia em abrigos, é obrigada a repousar sua cabeça em ambientes precários. Os alojamentos são superlotados, os quartos empilhados de camas, onde dormem conjuntamente homens, mulheres, adultos, crianças, doentes, sadios, sóbrios e bêbados. Sobre as pessoas que não podem pagar nem mesmo esse tipo de alojamento, o "General", responde:

Pois bem: dormem em qualquer lugar, nas esquinas, sob uma arcada, num canto qualquer onde a polícia ou os proprietários os deixem descansar tranquilos; alguns se acomodam em asilos construídos aqui e acolá pela beneficência privada, outros nos bancos dos jardins (...). (Ibidem) 
Cadernos de Estudos Sociais e Políticos, Rio de Janeiro, vol. 6, 2018.

Mais uma vez, evidencia-se o contraste social ao observar que esses desabrigados dormem "quase sob as janelas da rainha Vitória” (Engels, 2010, p. 75).

Verifica-se também as variações nas péssimas condições de habitação, como os porões, e a superlotação, que contribuem para o surgimento de moléstias entre os operários. $\mathrm{Na}$ cidade de Liverpool, "um bom quinto da população - isto é, mais de 45 mil pessoas - mora em pequenos porões, escuros e mal arejados, porões que, na cidade, totalizam 7.862” (Op. cit., p. 79). Já na cidade de Bristol, "foram visitadas 2.800 famílias operárias e comprovou-se que 46\% delas viviam em um único cômodo" (Op. cit., p. 80). Em um bairro chamado Little Ireland, em sua maioria composta por imigrantes irlandeses, "as casas são velhas, sujas e do tipo mais exíguo; as ruas, irregulares e nem todas pavimentadas, não são niveladas nem há rede de esgoto; imundície e lama, em meio a poças nauseabundas, estão por toda parte; daí a atmosfera, já enegrecida pela fumaça de uma dúzia de chaminés de fábricas, ser empestada” (Op. cit., p. 102). Além disso, “em todo bairro, para cada 120 pessoas há apenas uma instalação sanitária (quase sempre ocupada, é claro)" (Op. cit., p. 103). Os operários desses bairros vivem em condições subumanas: "quem aí vive deve realmente situar-se no mais baixo escalão da humanidade" (Op. cit., p. 102).

Em seu texto Contribuição ao Problema da Habitação, de 1872/73, Engels afirma "que não poderia existir sem crise da habitação uma sociedade na qual a grande massa trabalhadora não pode contar senão com um salário" (1976, p. 71). Manuel Castells, em suas pesquisas sobre o fenômeno urbano, corrobora Engels no tocante à dimensão estrutural da crise da habitação: "trata-se de uma defasagem necessária entre as necessidades, socialmente definidas, da habitação e a produção de moradias e de equipamentos residenciais" (1983, p. 183 e 185).

Além das péssimas condições de habitação, que em nada favorecem a saúde e o bem-estar dos trabalhadores, Engels chama a atenção para as fraudes, quantitativas e qualitativas, nas mercadorias encontradas no comércio voltado aos operários. "Os varejistas e os fabricantes adulteram todos os gêneros alimentícios do modo mais irresponsável, com inteiro desprezo pela saúde dos que devem consumi-los" (2010, p. 111). Por conta da pobreza acentuada em que se encontra o operário, "para quem uns poucos centavos representam muito" (Op. cit., p. 112), estes se veem obrigados a procurar os pequenos estabelecimentos:

onde muitas vezes pode comprar a crédito, lojas que, em função de seu pequeno capital e de suas desvantagens diante dos atacadistas, estão impossibilitadas de vender mercadorias da mesma qualidade ao mesmo preço dos grandes estabelecimentos e que, por causa dos preços baixos que lhes pedem seus fregueses e da concorrência, são constrangidas a fornecer, intencionalmente ou não, produtos adulterados. (Engels, 2010, p. 112) 
Cadernos de Estudos Sociais e Políticos, Rio de Janeiro, vol. 6, 2018.

Todavia, não é apenas no que diz respeito à qualidade que o operário é ludibriado, mas também na quantidade dos produtos. "Em sua grande maioria, os pequenos comerciantes têm medidas e pesos adulterados e os relatórios policiais registram diariamente um número incrível de delitos desse gênero" (Op. cit., p. 113). Engels conclui seu raciocínio alegando que "as mesmas razões pelas quais os operários são vítimas principais das fraudes na qualidade explicam que também o sejam no que toca às fraudes relativas à quantidade" (Op. cit., p. 114).

O alcoolismo é outro problema social de profunda relevância e que vitimiza boa parte dos trabalhadores. Engels apresenta alguns elementos que favoreceriam o alcoolismo:

\footnotetext{
O trabalhador retorna à casa fatigado e exausto; encontra uma habitação sem nenhuma comodidade, úmida, desagradável e suja; tem a urgente necessidade de distrair-se; precisa de qualquer coisa que faça seu trabalho valer a pena, que torne suportável a perspectiva do amargo dia seguinte. (Op. cit., p. 142, os grifos são do autor).
}

Em A Situação, refuta-se a ideia de que o alcoolismo seja "um vício de responsabilidade individual" (Ibidem), pois "a necessidade física e moral leva uma grande parte dos trabalhadores a sucumbir ao álcool" (Ibidem) e, por conta de uma educação deficitária, torna-se impossível "proteger os mais jovens contra essa tentação" (Ibidem). "É inevitável que o alcoolismo provoque efeitos destrutivos sobre os corpos e os espíritos de suas vítimas” (Op. Cit., p. 143).

O quadro observado por Engels em nada contribui para a qualidade de vida dos operários. As fábricas poluem o ar e os rios da cidade, as longas jornadas de trabalho inviabilizam a realização de atividades físicas e o acesso aos melhores alimentos vendidos no comércio, uma vez que o trabalhador não dispõe de tempo para ir às feiras, restando-lhe apenas o final do dia, quando só se tem acesso aos piores alimentos. Além disso, os baixos salários levam-nos a consumir produtos adulterados, vendidos pelos pequenos varejistas; e os impendem de ter acesso à moradia de qualidade, tendo, frequentemente, que habitar porões úmidos, em bairros sem serviços de coleta de lixo, sem acesso à água encanada, meios de transporte e com uma estrutura arquitetônica que não favorece a circulação e renovação do ar.

O desemprego acentua a vulnerabilidade dos trabalhadores, uma vez que estes não têm dinheiro para ter acesso a nada, mesmo que seja de forma precária.

Os desempregados, vistos por Engels como um elemento estrutural da dinâmica do capitalismo industrial, e por ele nomeados de "exército de trabalhadores desempregados", são os mais vulneráveis, os que estão mais sujeito à morte por fome e frio, uma vez que não possuem

5 Posteriormente, Marx, em O Capital, irá chamá-los de exército industrial de reserva, uma clara demonstração da influência de Engels sobre seu espírito. 
Cadernos de Estudos Sociais e Políticos, Rio de Janeiro, vol. 6, 2018.

recursos para se alimentar ou pagar a diária de um alojamento. Também estão mais sujeitos a cometer crimes, como roubos, furtos e assassinatos, além de ficarem mais expostos à violência policial.

As grandes cidades são constituídas por contradições internas, e sua organização interna está em posição "diametralmente oposta” ao campo. Na obra A Ideologia Alemã, Engels e Marx afirmam que "a cidade é de pronto, o fato da concentração da população, dos instrumentos de produção, do capital, das fruições, das necessidades" (2007, p. 52) em quanto que o campo é o espaço do isolamento e da solidão. Dessa forma os autores trazem à tona a ideia de que a cidade é a manifestação dos "condicionantes sociais e econômicos que se expressam por meio de uma forma, especifica, de organização da população (em classes) e dos instrumentos de produção (meios técnicos científicos informacionais) em um só lugar”. (Pereira, 2018, p. 37). A oposição entre o campo e a cidade não é algo que pode ser superada "pela mera vontade", neste sentido a consciência de classe é um pressuposto material fundamental para esta superação.

\section{À GUISA DE CONCLUSÃO}

Engels enxergava na cidade um laboratório de investigação do desenvolvimento do capitalismo, das condições de vida do proletariado, e da transformação revolucionária da sociedade. Em $A$ Situação, apresenta um quadro caótico, de desigualdade social, miséria, violência e epidemias. As descrições e análises de alguns elementos que constituem a dinamicidade das grandes cidades, como o processo de urbanização pela densidade demográfica, a concorrência, o individualismo, os impactos ecológicos, as condições de vida dos trabalhadores no que diz respeito ao acesso à cidade, à saúde e educação, nos permitiram alcançar a proposta inicial desta pesquisa, que era identificar as principais contribuições de Friedrich Engels para o campo da Sociologia Urbana. O estudo dessa obra também nos permitiu verificar o quanto ela ainda é atual, como bem chama a atenção Yvonne Maggie (2011) ao afirmar que as descrições contidas em $A$ Situação se assemelham em muitos aspectos a realidade de muitas das grandes cidades do Brasil.

O pioneirismo de $A$ Situação traz uma série de inovações nos estudos sobre as cidades, entre elas a variabilidade das de fontes de investigação e seu caráter etnográfico. Além disso, essa obra forma um quadro analítico extremamente complexo que contempla as múltiplas determinações dos diversos fenômenos sociais interconectando-os organicamente, estabelecendo 
Cadernos de Estudos Sociais e Políticos, Rio de Janeiro, vol. 6, 2018.

diferentes escalas gradativas entre eles e descrevendo-os com riqueza de detalhes. A envergadura dessa obra, com os posicionamentos políticos do autor frente aos problemas examinados, influenciou diversos estudiosos do fenômeno urbano como Henry Lefebvre, Manuel Castells e Eric Hobsbawm.

Não foi possível explorar plenamente outras dimensões importantes dessa obra, como as péssimas condições de trabalho nas fábricas, e as diversas práticas adotadas pelos industriais que contribuíam para a miséria do trabalhador - como as multas por atraso, o machismo, as organizações operárias, o sistema judiciário, o desenvolvimento tecnológico, a educação pública, a "hipocrisia ideológica" da burguesia, a filantropia de instituições burguesas e religiosas, as crises econômicas etc.

O contexto vivenciado pela classe trabalhadora inglesa é descrita por Engels com riqueza de detalhes. Angelo Silva afirma que o "General" "consegue articular a frieza de dados estatísticos com o dia a dia das pessoas" (2009, p, 34). Engels não apenas relata, mas assume de forma honesta uma posição política decididamente comunista frente a seu objeto de estudo; ou seja, enxerga o jogo das interações sociais pela ótica do proletariado, produzindo uma obra política que provoca inquietações no seu leitor e que é, ao mesmo tempo, rigorosamente científica. A relação sujeito objeto nessa obra se diferencia radicalmente das conclusões epistemológicas das correntes positivistas que defendem um modelo de objetividade científica que passa pela neutralidade e imparcialidade, na qual o cientista não deve se posiciona frente ao seu objeto, estabelecendo uma relação puramente descritiva e analítica. Michael Löwy salienta que "o ponto de vista de classe e o conhecimento científico não são contraditórios" (2006:106), pois o posicionamento político de uma determinada classe não implica em perda de valor científico de uma dada teoria.

O otimismo "ingênuo" de Engels está em evidência, mas, como bem estabelece José Paulo Netto (2004), o contexto propiciava esse otimismo, que é assumido pelo próprio "General” no prefácio à edição inglesa de 1892: “não me passou pela cabeça retirar do texto as várias profecias - especialmente aquela sobre uma iminente revolução social na Inglaterra - devido ao meu entusiasmo revolucionário daqueles anos” (Engels, 2010, p. 351).

Um dos argumentos centrais na obra de Engels, que está intimamente conectado ao seu otimismo revolucionário, é o fato de que o pior que o capitalismo pode produzir é reduzir os indivíduos a uma condição de animalidade. Lutar contra a opressão é um elemento essencial, fundamental e irredutível para retirá-los dessa condição. Engels apresenta duas alternativas para os operários: “resignar-se à sua sorte, torna-se um 'bom' trabalhador, servir 'fielmente' aos interesses da burguesia - e, nesse caso, torna-se realmente um animal - ou resistir, combater tanto quanto 
Cadernos de Estudos Sociais e Políticos, Rio de Janeiro, vol. 6, 2018.

possas por sua dignidade humana - o que só lhe é possível lutando contra a burguesia” (Engels, 2010, p. 158).

Para Engels, a classe trabalhadora não era apena uma "massa sofredora" que se encontrava sob o "jugo do capital”, como acreditavam os owenistas; mas eram pessoas que lutavam "corajosamente por uma existência humana digna" (Instituto de Marxismo-Leninismo do CC-

PCUS. 1986:64). É na dinâmica das lutas de classes que Engels sublinhará “particularmente o papel dos grandes centros industriais no desenvolvimento do movimento operário"; o surgimento dos primeiros operários que começaram a refletir sobre sua condição, pois foi nas grandes cidades, com suas contradições internas, que tiveram origem a cultura combativa dos trabalhadores através da criação de diversas associações proletárias (como as Trade Unions), o cartismo, o socialismo e suas teorias libertárias e revolucionárias.

\section{BIBLIOGRAFIA}

CASTELLS, Manuel. A Questão Urbana. Rio de Janeiro: Paz e Terra, 1983.

CASTELLUCCI, Aldrin. A. S. Engels e a história social do trabalho. In. MOURA, Mauro Castelo Branco de; FERREIRA, Muniz; MORENO, Ricardo (orgs.). Friedrich Engels e a ciência contemporânea. Salvador: EDUFBA, 2007, pp. 21-8.

ENGELS, Friedrich. A Situação da Classe Trabalbadora na Inglaterra. São Paulo: Boitempo 2010. 1976, 39-116.

. Contribuição ao problema da habitação. Textos: volume II. São Paulo: Edições Sociais,

- ENGELS, Friedrich. Letters from Wuppertal. In: Marx Engels Collected Works (MECW). Vol. 2. 1838-1842. Londres: Lawrence \& Wishart, 2010, pp. 07-25.

. Princípios Básicos do Comunismo. Lisboa: Avante, 1982.

. MARX, Karl. A Ideologia Alemã. São Paulo: Boitempo 2007.

HOBSBAWM, Eric. A Era do Capital: 1848/1875. Rio de Janeiro: Paz e Terra, 1977.

. Como Mudar o Mundo. São Paulo: Companhia das Letras, 2011.

Prólogo. In: ENGELS, Friedrich. A Situação da Classe Trabalhadora em Inglaterra. Porto:

Afrontamento, 1975, pp. 05-22. 
Cadernos de Estudos Sociais e Políticos, Rio de Janeiro, vol. 6, 2018.

HUNT, Tristran. Comunista de Casaca: a vida Revolucionaria de Friedrich Engels. São Paulo: Record, 2010.

INSTITUTO de Marxismo-Leninismo do CC-PCUS. Friedrich Engels: Biografia. Lisboa, Edições Avante! 1986.

LEFEBVRE, Henri. A Cidade do Capital. Rio de Janeiro, DP\&A, 2001.

LENIN, Vladimir Ilych. A Correspondência Entre Marx e Engels, s.d. 2016. Disponível em: $<$ https://www.marxists.org/portugues/lenin/1913/mes/correspondencia.htm>. Acesso em: 06 de jan. 2017.

LÖWY, Michael. Ideologias e ciência social: elementos para uma análise marxista. São Paulo: Cortez, 2006.

MAGGIE, Yvonne. A Grande Cidade. G1, 2011. Disponível em: <http://g1.globo.com/platb/yvonnemaggie/2011/10/21/a-grande-cidade/>. Acesso em: 07 de jan. 2017.

MELO, Wanderson Fabio de. Friedrich Engels e a questão habitacional: o pauperismo socialmente produzido no sistema capitalista e as condições de moradia. In: Verinotio, Belo Horizonte, $\mathrm{n}^{\circ} 20$, ano X, 2015. Disponível em: <http://www.verinotio.org/conteudo/0.8126378458111.pdf>. Acesso em: 06 de Jan. 2017.

NETTO, José Paulo. Marxismo impenitente: contribuição à história das ideias marxistas. São Paulo: Cortez, 2004.

PARK, Robert Ezra. A Cidade: Sugestões para a investigação do comportamento humano no meio urbano. In: VELHO, Otávio Guilherme. O Fenômeno Urbano. Rio de Janeiro: Zahar, 1967, pp. 2566.

PEREIRA, Jesus Marmanillo As cidades na perspectiva do materialismo histórico: Marx, Engels e as cidades industriais. In: Sociabilidades Urbanas, João Pessoa, v.2, n.4, 2018. Disponível em: <http://www.cchla.ufpb.br/grem/sociabilidadesurbanas/SocUrbs\%20V2N4\%202018\%20Mar manilloArtigo.pdf>. Acesso em: 06 de Jan. 2019.

ROLNIK, Raquel. O que é cidade. São Paulo: Brasiliense, 1975.

SILVA, Angelo. Sociologia Urbana. Curitiba: IESDE Brasil S.A, 2009.

WILSON, Edmund. Rumo à Estação Finlândia: escritores e atores da história. São Paulo: Companhia da Letras, 1986. 